\title{
Synaptotagmin I delays the fast inactivation of Kv1.4 channel through interaction with its N-terminus
}

\author{
Chunliang Xie ${ }^{1,2 \dagger}{ }^{,}$Haibo Su ${ }^{1 \dagger}$, Tianyao Guo ${ }^{1}$, Yizhong Yan ${ }^{1}$, Xiaozhen Peng ${ }^{1}$, Rui Cao ${ }^{1}$, Ying Wang ${ }^{1}$, Ping Chen ${ }^{1}$, \\ Xianchun Wang ${ }^{1 *}$ and Songping Liang ${ }^{1 *}$
}

\begin{abstract}
Background: The voltage-gated potassium channel Kv1.4 is an important A-type potassium channel and modulates the excitability of neurons in central nervous system. Analysis of the interaction between Kv1.4 and its interacting proteins is helpful to elucidate the function and mechanism of the channel.

Results: In the present research, synaptotagmin I was for the first time demonstrated to be an interacting protein of Kv1.4 and its interaction with Kv1.4 channel did not require the mediation of other synaptic proteins. Using patch-clamp technique, synaptotagmin I was found to delay the inactivation of Kv1.4 in HEK293T cells in a $\mathrm{Ca}^{2+}$-dependent manner, and this interaction was proven to have specificity. Mutagenesis experiments indicated that synaptotagmin I interacted with the N-terminus of Kv1.4 and thus delayed its N-type fast inactivation.
\end{abstract}

Conclusion: These data suggest that synaptotagmin I is an interacting protein of Kv1.4 channel and, as a negative modulator, may play an important role in regulating neuronal excitability and synaptic efficacy.

Keywords: Synaptotagmin I, Kv1.4, Interaction, Inactivation kinetics, Regulation

\section{Background}

Voltage-gated potassium $(\mathrm{Kv})$ channels set the resting membrane potential and shape the action potential waveform and frequency to tune excitability in the nervous system [1]. A-type $\mathrm{Kv}$ channels activate at subthreshold membrane potentials, inactivate rapidly with a time course of less than $100 \mathrm{~ms}$, and rapidly recover from inactivation. In presynaptic terminals, A-type channel inactivation is responsible for frequency-dependent action potential broadening, a phenomenon that allows nerve terminals to regulate the neuronal excitability and synaptic transmission during high-frequency stimulation [2]. Kv1.4, a prominent member of the $\mathrm{Kv} 1$ family [3], is a fast inactivation A-type $\mathrm{Kv}$ channel $[4,5]$ which is widely distributed in the central nervous system, where it is concentrated in axonal membranes or near axon [6], and also presents in the

\footnotetext{
* Correspondence: wang_xianchun@263.net; liangsp@hunnu.edu.cn ${ }^{\dagger}$ Equal contributors

'Key Laboratory of Protein Chemistry and Developmental Biology of Ministry of Education, College of Life Sciences, Hunan Normal University, Changsha, Hunan 410081 , P. R. China

Full list of author information is available at the end of the article
}

cardiac ventricular endocardium [7]. The up-regulation of Kv1.4 expression could lead to hypertrophy and heart failure, indicating that the behavior of this channel is of particular clinical importance $[8,9]$.

Although Kv1.4 contributes to a presynaptic A-type current to regulate neurotransmitter release [10], how the Kv1.4 is regulated has not been fully understood. The native Kv1.4 channel often forms a tetramer by $\alpha$ subunits. However, the properties of Kv1.4 channel are modulated by a family of regulatory proteins in addition to the $\alpha$ subunits, such as $\operatorname{Kv} \beta$ subunits that coassemble with the Kvo proteins through direct protein-protein interaction and affect the gating, permeability and pharmacology of the ion channel. Furthermore, the $\operatorname{Kv} \beta$ subunits influence the number and subcellular localization of the ion channel in plasma membrane and synapse by promoting its trafficking and targeting processes [11]. In addition, intracellular signaling proteins can also modulate Kv1.4 channel function. For example, Kv1.4 channel is an in vivo substrate for CaMKII [12]. The phosphorylation of Kv1.4 by CaMKII can modulate the inactivation kinetics of this channel. It is 
suggested that kinases and phosphatases, as well as other signaling and scaffolding proteins, may be intimately associated with the ion channel in a regulatory protein complex [13]. Therefore, the functional complexity of Kv1.4 will increase as additional associated proteins are found.

In the present research, synaptotagmin $\mathrm{I}, \mathrm{a} \mathrm{Ca}^{2+}$ sensor playing a key role in the regulation of synaptic vesicle exocytosis [14], was shown by proteomic strategy to associate with Kv1.4 channel-containing complexes affinity purified from rat hippocampus. Further experiments revealed that there was specific and $\mathrm{Ca}^{2+}$-dependent interaction between synaptotagmin I and Kv1.4, and the interaction was not mediated by other synaptic proteins. Such specific interaction occurred between synaptotagmin I and the $\mathrm{N}$-terminus of Kv1.4 channel and thus the fast N-type inactivation of the channel was delayed. The functional consequence of the interaction between synaptotagmin I and Kv1.4 is that the inactivation kinetics of Kv 1.4 is specifically modulated by synaptotagmin I, leading to the decrease in the neuronal excitability.

\section{Results \\ Affinity purification and proteomic analysis of native Kv1.4 channel complex}

Affinity purification and proteomic analysis were employed to identify the components of native Kv1.4 channel complex to find new modulatory factors of the ion channel. After the Kv1.4 channel complex was affinity purified with a Kv1.4-specific antibody (anti-Kv1.4) from plasma membrane-enriched protein fractions prepared from rat hippocampus, it was subjected to SDS-PAGE, using preimmunization immunoglobulins G (IgGs) as a negative control. The silver-stained protein bands obtained specifically with anti-Kv1.4 but not with preimmunization IgGs (Figure 1A) were selected for protein identification with CapLC-MS/MS. It was shown that the identified proteins included Kv1.1 protein, also an A-type Kv channel that had already been demonstrated to interact with Kv1.4 [15], several typical constituents of the synaptic exocytosis machinery (such as syntaxin1B, rab3A and synaptotagmin I) and $\mathrm{Na}^{+} / \mathrm{K}^{+}$-ATPase as well as cytoskeleton proteins (tubulin and actin) (Table 1). Synaptotagmin I was identified in the bands at about $47 \mathrm{kDa}$ and $65 \mathrm{kDa}$ (Figure 1A), suggesting that the protein exits in different forms due to the post-translation modification [16]. In view of the functional significance of synaptotagmin [14] and its abundant copurification with Kv1.4 using antiKv1.4 antibody (Figure 1A), the possible interaction between synaptotagmin I and Kv1.4 channel protein was further examined in subsequent investigations.

The coassembly of synaptotagmin I and Kv1.4 channel complex was confirmed by subsequent reverse copurification from the rat hippocampal plasma membrane-enriched protein preparations with a synaptotagmin I -specific antibody (anti-synaptotagmin I). As illustrated by the western blot in Figure 1B, Kv1.4 was copurified by the antisynaptotagmin I but not by the pool of preimmunization IgGs used as a control. These results further demonstrated that synaptotagmin I can associate with Kv1.4 channel complex.

\section{Overlapping expression profile of synaptotagmin I and Kv1.4 in hippocampus}

Information regarding the distributions of synaptotagmin I and Kv1.4 in neurons is helpful to analyze their interaction. We performed dual labeling experiments to determine whether synaptotagmin I and Kv1.4 are colocalized in hippocampal neurons, as would be predicted if the interactions reported here are of physiological relevance. The expression profiles of synaptotagmin I and Kv1.4 in the hippocampus were analyzed by immunohistochemistry on adult rat brain sections and the specificity of the staining was confirmed by the preimmunization serum. The results in Figure 1C show that in the hippocampus Kv1.4 is predominantly expressed in the pyramidal cells of CA1-CA3 regions and the molecular layers of the dentate gyrus (b and e in Figure 1C), while synaptotagmin I staining is predominantly seen in the CA3 pyramidal cells but not the molecular layers of the dentate gyrus (c and $\mathrm{f}$ in Figure $1 \mathrm{C}$ ). Both proteins are colocalized in the CA3 pyramidal cells ( $\mathrm{g}$ to $\mathrm{i}$ in Figure 1C). These data demonstrate that synaptotagmin I has a narrower distribution range and its coexpression with Kv1.4 channel in CA3 pyramidal cells implies their potential physical relevance in the neurons.

\section{Interaction between synaptotagmin I and Kv1.4 coexpressed in HEK293T cells}

Although affinity purification and proteomic analysis suggested that synaptotagmin I could interact with Kv1.4 channel complex, we were not sure whether the interaction between synaptotagmin I and Kv1.4 was mediated by other protein(s) especially the synaptic proteins. To test the authenticity of the interaction between the two proteins, recombinant full-length synaptotagmin I and Kv1.4 were expressed in HEK293T cells. Immunoprecipitations with an antibody against synaptotagmin I (or with nonspecific control IgGs) were performed from cotransfected cell extract. The precipitates were tested for the presence of synaptotagmin I and Kv1.4 by western blot. The results (Figure 2A) showed that Kv1.4 was efficiently coprecipitated with the antibody against synaptotagmin I. At the same time, an immunofluorescence analysis on the HEK293T cells cotransfected with synaptotagmin I and Kv1.4 cDNAs was carried out. The results (Figure 2B) showed that both proteins were colocalized in the plasma membrane of HEK293T cells. These data demonstrated that synaptotagmin I and Kv1.4 have co-localization in the 

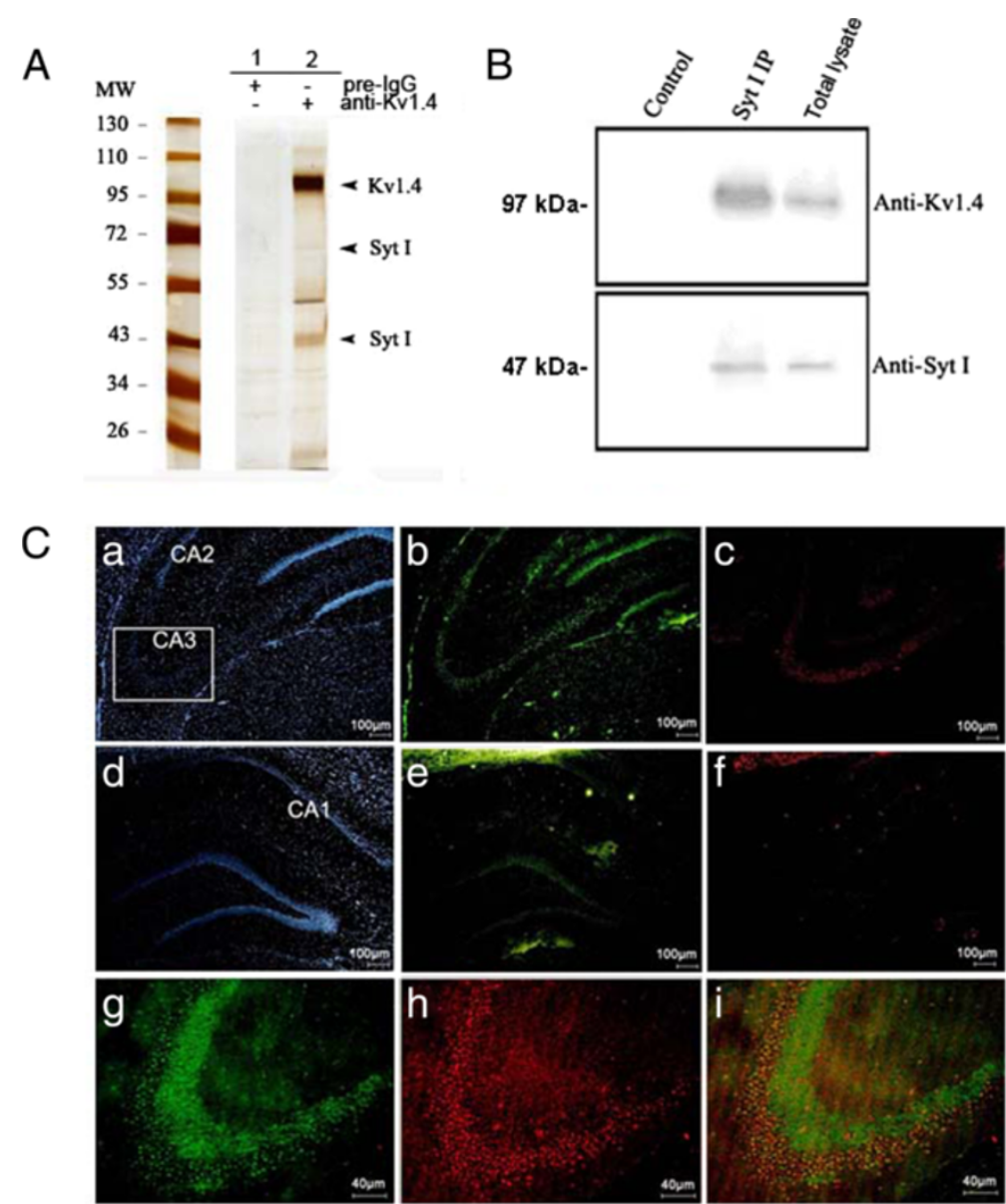

Figure 1 Validation of interaction between synaptotagmin I and Kv1.4 channel. (A) Silver-stained SDS-PAGE of the protein complexes affinity purified from rat hippocampal plasma membrane-enriched fraction either with a Kv1.4-specific antibody (anti-Kv1.4) or a preimmunisation IgG pool (Pre-lgG). Arrowheads denote the bands identified by nano-LC tandem mass spectrometry as Kv1.4 and synaptotagmin I, respectively. (B) Western blot showing reverse purification of Kv1.4 from the same fraction with anti-synaptotagmin I. (C) Immunohistochemical analysis of the colocalization of synaptotagmin I and Kv1.4 in rat hippocampus. (a)-(c) show the localizations of pyramidal cell nuclei, Kv1.4 and synaptotagmin I in the CA2- CA3 regions, respectively. (d)-(f) show the localizations of pyramidal cell nuclei, Kv1.4 and synaptotagmin I in the CA1 region and denote gyrus, respectively. (g)-(i) are the enlarged images of CA3 region showing the localizations of Kv1.4 (g), synaptotagmin I ( $h$ ) and their colocalization (i) in this region.

Table 1 Proteins affinity purified with anti-Kv1.4 from rat hippocampal plasma membranes-enriched protein fraction and identified by CapLC tandem mass spectrometry

\begin{tabular}{ll}
\hline Categorization & Proteins \\
\hline Kv a subunits & Kv1.1, Kv1.4 \\
Synaptic proteins & $\begin{array}{l}\text { Syntaxin } 1 \mathrm{~B} \text {, synaptotagmin I, synapsin, } \\
\text { Rab3A, syntaxin-binding protein } 1\end{array}$ \\
Transporters & $\mathrm{Na}^{+} / \mathrm{K}^{+}$ATPase $(\mathrm{a}, \beta)$ \\
Cytoskeleton proteins & Actin, tubulin \\
\hline
\end{tabular}

Procedures used for affinity purification and mass spectrometry as well as the criteria for protein identification are detailed in the Experimental Procedures. plasma membrane and the interaction between them does not require the mediation of other synaptic proteins.

\section{Synaptotagmin I modulates the inactivation kinetics of Kv1.4 in HEK293T cells}

Given the overlapping in expression pattern and the importance of the two proteins in neurotransmission, the impact of the synaptotagmin I protein on Kv1.4 channel gating in HEK293T cells was further investigated with whole-cell patch-clamp technique. Figure 3A shows the rapidly inactivating A-type $\mathrm{K}^{+}$currents recorded in response to depolarizing voltage steps (from $-80 \mathrm{mV}$ to $+70 \mathrm{mV}, 10 \mathrm{mV}$ increment) in the whole-cell patchclamp experiments with HEK293T cells that coexpressed Kv1.4 and EGFP. The decay of these A currents was adequately fit with a single exponential yielding a 


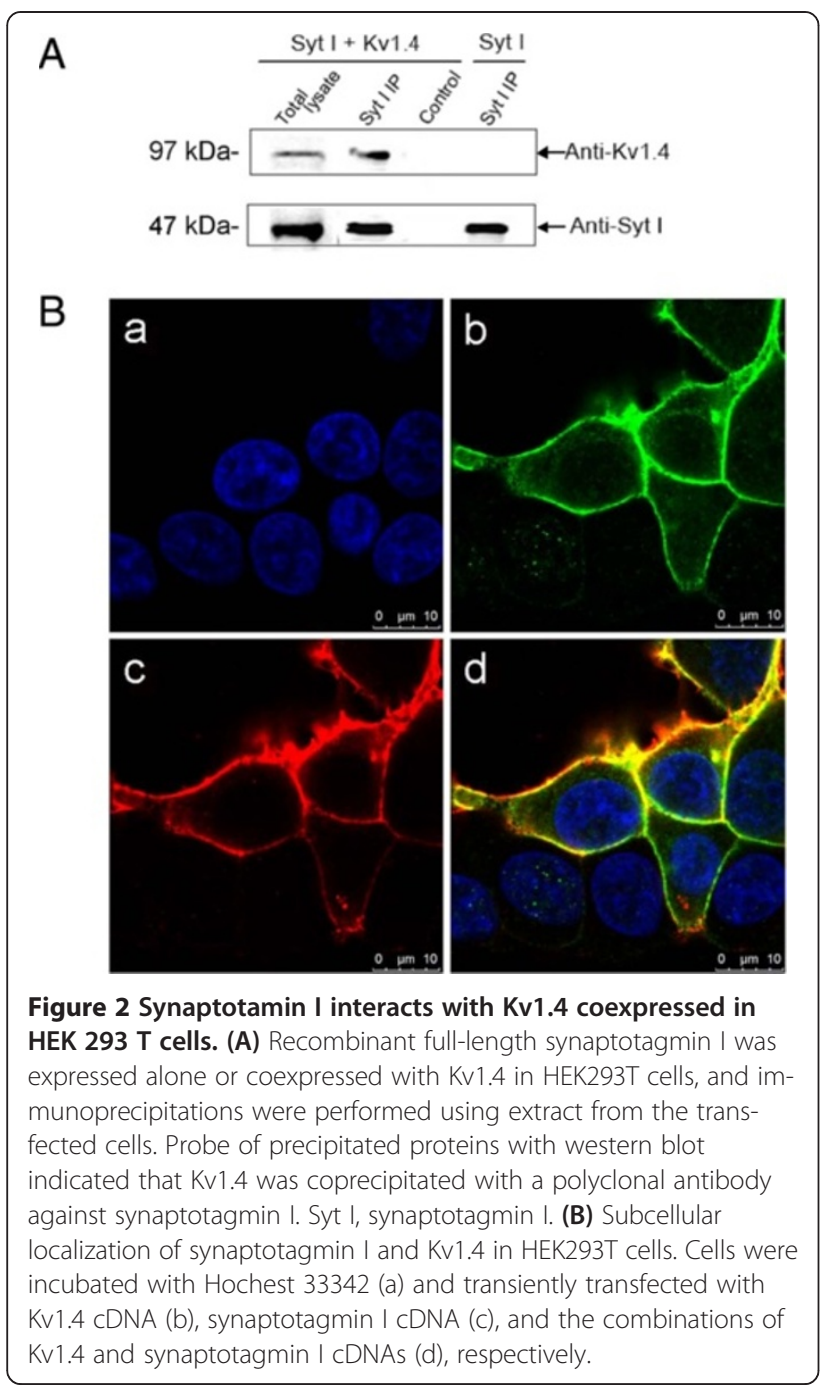

voltage-dependent inactivation time constant $\left(\tau_{\text {inact }}\right)$ of $31.1 \pm 2.3 \mathrm{~ms}(\mathrm{n}=13)$ at a membrane potential of $+30 \mathrm{mV}$ (Figure 3C and 3D). Coexpression of synaptotamin I and Kv1.4 markedly slowed the inactivation of Kv1.4 channel, with $\tau_{\text {inact }}$ of $64.8 \pm 4.5 \mathrm{~ms}(\mathrm{n}=9)$ at $+30 \mathrm{mV}$, increased by more than 2-fold (Figure 3B-3D). In contrast, voltagedependent activation of the channels was unaffected by the coexpressed synaptotagmin I (Figure 3E), suggesting that synaptotamin I only affects the inactivation kinetics of Kv1.4 channel.

\section{Modulation of Kv1.4 inactivation by synaptotagmin I requires intracellular $\mathrm{Ca}^{2+}$}

Considering that synaptotagmin I takes part in the neurotransmission process as a $\mathrm{Ca}^{2+}$ sensor [17], we examined whether manipulation of cytosolic $\mathrm{Ca}^{2+}$ might influence the effects that synaptotagmin I had on Kv1.4 currents. After Kv1.4 cDNA was expressed alone or coexpressed with synaptotagmin I cDNA in HEK293T cells, the cells were incubated for a period of $20-26 \mathrm{~h}$ with the membrane- permeable $\mathrm{Ca}^{2+}$ chelator, BAPTA-AM $(10 \mu \mathrm{M}$ in $0.1 \%$ DMSO), or only with the solvent $0.1 \%$ DMSO as a control. The incubation with BAPTA-AM was started 1-day after transfection, when protein synthesis or trafficking was expected to occur at high rates. As a result, the inactivation of Kv1.4 was found to be delayed by the coexpressed synaptotagmin I when the HEK293T cells were incubated with solvent DMSO (Figure 4A) and the $\tau_{\text {inact }}$ values of Kv1.4 channel expressed alone and co-expressed with synaptotagmin I were $38.1 \pm 2.3 \mathrm{~ms}(\mathrm{n}=9)$ and $68.8 \pm$ $2.6 \mathrm{~ms}(\mathrm{n}=9)$ at a membrane potential of $+30 \mathrm{mV}$, respectively $(\mathrm{p}<0.05)$ (Figure $4 \mathrm{C})$. In contrast, the effect of synaptotagmin I on Kv1.4 inactivation was prevented when HEK293T cells were incubated with the BAPTA-AM (Figure 4B) and the $\tau_{\text {inact }}$ values of the channel under the two different conditions were not significantly different $(\mathrm{P}>0.05)$ (Figure $4 \mathrm{C})$. These results demonstrated that modulation of Kv1.4 inactivation by synaptotagmin I requires intracellular $\mathrm{Ca}^{2+}$.

In order to further probe into the requirement for calcium ions, we used patch-clamp technique on HEK293T cells to investigate the effect of different concentrations of free calcium on the slowed inactivation of Kv1.4 caused by synaptotagmin I. To obtain specific free $\mathrm{Ca}^{2+}$ concentrations, $1 \mathrm{mM}$ EGTA was added to the bath solution, and different concentrations of $\mathrm{CaCl}_{2}$ were added as calculated with the CABUF program. The results showed that, as the concentrations of added free calcium ions were increased from $50 \mathrm{nM}$ to $1600 \mathrm{nM}$, the inactivation traces of $\mathrm{Kv} 1.4$ was shifted to the right accordingly. For example, at a free calcium ion concentration of $50 \mathrm{nM}$, Kv1.4 current inactivated rapidly, with a $\tau_{\text {inact }}$ value of $64.8 \pm 4.5 \mathrm{~ms}$ $(\mathrm{n}=10)$ at $+30 \mathrm{mV}$; Upon application of $1600 \mathrm{nM}$ free calcium ions, the inactivation of Kv1.4 was greatly slowed, resulting in a $\tau_{\text {inact }}$ value of $223.6 \pm 17.3 \mathrm{~ms}(\mathrm{n}=10)$ (Figure 4D and 4E). In addition, in the low concentration range from $50 \mathrm{nM}$ to $500 \mathrm{nM}$, there was a nearly linear increase in the $\tau_{\text {inact }}$ values (Figure $4 \mathrm{E}$ ). These data showed that the effect of $\mathrm{Ca}^{2+}$ on the delay of Kv1.4 channel inactivation caused by synaptotagmin I is dose-dependent.

\section{Synaptotagmin I specifically modulates Kv1.4 channel currents}

In order to investigate the specificity for the modulation of Kv1.4 channel by synaptotagmin I, we examined whether synaptotagmin I also influenced other $\mathrm{Kv}$ channels. We chose Kv4.1, Kv4.2 and Kv4.3 of Kv4 family as experimental materials, because all of them and Kv1.4 express Atype currents and have similar inactivation mechanisms [18]. After the Kv4 plasmids were separately transfected alone or cotransfected with synaptotagmin I plasmid in HEK293T cells, the Kv channel kinetics were examined with whole-cell patch-clamp technique. Figure 5A shows the effect of synaptotagmin I on Kv4.1 channel. It could be 


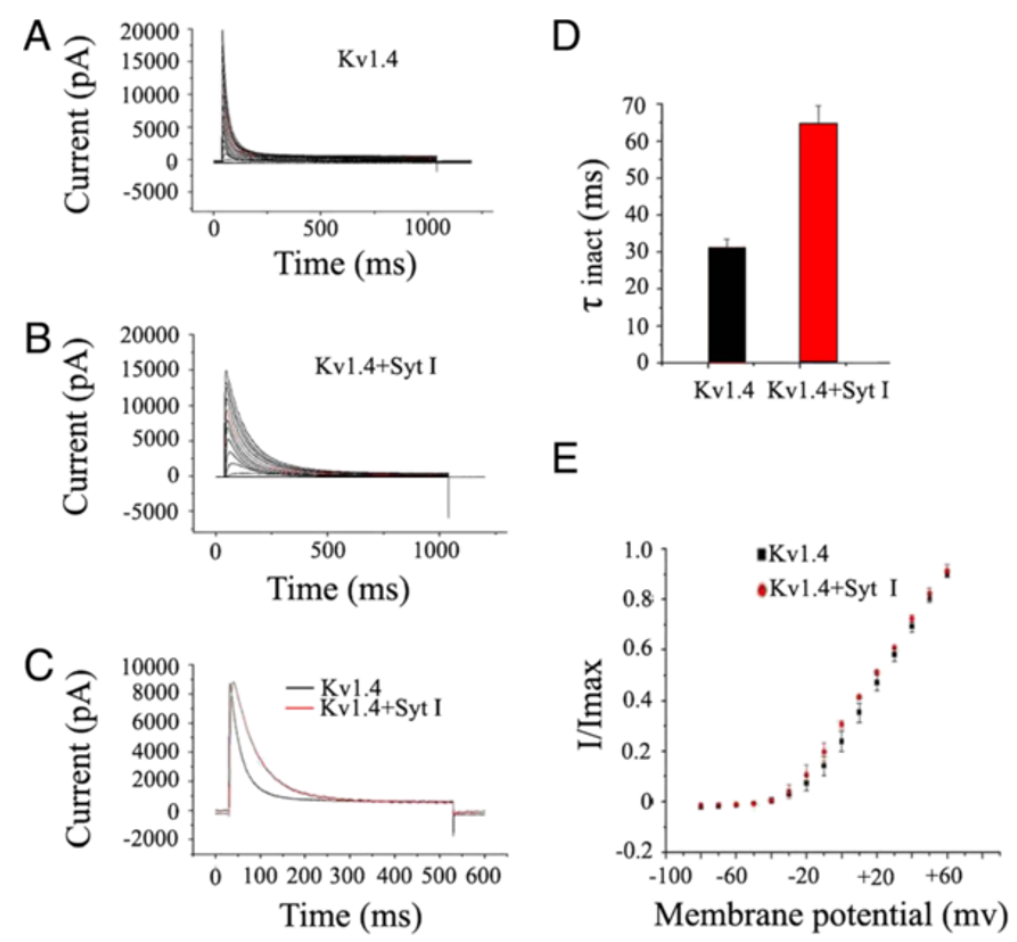

Figure 3 Effects of synaptotagmin I on Kv1.4 kinetics expressed in HEK293T cells. (A) Representative traces of Kv1.4 currents expressed alone. (B) Representative traces of Kv1.4 currents coexpressed with synaptotagmin I. Currents were elicited by depolarizing steps from -80 to $70 \mathrm{mV}$ in $10 \mathrm{mV}$ increments every $45 \mathrm{~s}$ from a holding potential of $-80 \mathrm{mV}$. (C) Currents recorded upon depolarization to $+30 \mathrm{mV}$. (D) Inactivation time constants ( $\tau_{\text {inact }}$ ) of the indicated channel obtained at $+30 \mathrm{mV}$. Data are expressed as mean $\pm S D$. The $T_{\text {inact }}$ of Kv1.4 current expressed alone was $31.1 \mathrm{~ms} \pm 2.3 \mathrm{~ms}(\mathrm{n}=13)$, compared with $64.8 \pm 4.5 \mathrm{~ms}(\mathrm{n}=9)$ for Kv1.4 current coexpressed with synaptotagmin I ( $<<0.05)$. (E) Activation curves of Kv1.4 and Kv1.4/synaptotagmin I. Current amplitudes recorded from the channels were normalized to the maximal response at $+30 \mathrm{mV}$ and plotted as a function of the membrane potential.

found from the representative Kv4.1 current traces at $+30 \mathrm{mV}$ (left) that two current curves in the presence or absence of synaptotagmin I were very close to each other, with the $\tau_{\text {inact }}$ (middle) and activation current amplitude (right) values being not significantly different $(\mathrm{P}>0.05)$. Likewise, Kv4.2 and Kv4.3 channels were not significantly affected by the coexpressed synaptotagmin I (Figure 5B and 5C). These results demonstrated that the interaction between synaptotagmin I and Kv1.4 is not a general feature of A-type potassium channels and the modulation of Kv1.4 by synaptotagmin I has specificity.

\section{$\mathrm{Kv} 1.4 \mathrm{~N}$-terminus is responsible for the interaction with synaptotagmin I}

Kv1.4 channel has been demonstrated to exhibit slow $\mathrm{C}-$ and fast $\mathrm{N}$-type inactivation, the latter incorporating an N-terminal "ball and chain" motif on the $\alpha$-subunit to block the channel pore [19]. To be certain whether synaptotagmin I affects C-type or N-type inactivation of Kv1.4, two Kv1.4 cDNA mutants were constructed: $\mathrm{Kv1} .4 \Delta \mathrm{N}$ and Kv1.4[K532Y]. Kv1.4 $\Delta \mathrm{N}$ lost $\mathrm{N}$-type inactivation due to the deletion of amino acid residues 2-146 but retained C-type inactivation. Kv1.4[K532Y] had N-type inactivation but limited C-type inactivation due to a K-to-Y mutation [5]. The effects of synaptotagmin I on Kv1.4 $\Delta \mathrm{N}$ currents are shown in Figure 6. It can be seen that both of the activation and inactivation of Kv1.4 $\Delta \mathrm{N} \mathrm{mu-}$ tant were not significantly affected by the coexpressed synaptotagmin I (Figure 6B-6E). However, in view of the huge delay of inactivation in $\mathrm{Kv} 1.4 \Delta \mathrm{N}$ mutant itself (Figure $6 \mathrm{~A}$ ), it is difficult to expect to detect a further delay by the coexpression of synaptotagmin I. Therefore, it could not be concluded based on the results that the C-type inactivation of Kv1.4 was not affected by synaptotagmin I (see Discussion). In contrast, as shown in Figure 7A and 7B, the inactivation of Kv1.4 [K532Y] was markedly delayed by the coexpressed synaptotagmin I. At a membrane potential of $+30 \mathrm{mV}$, the $\tau_{\text {inact }}$ of $\mathrm{Kv} 1.4$ [K532Y] was $36.6 \pm 1.3 \mathrm{~ms}$ $(\mathrm{n}=9)$, compared with $64.5 \pm 1.6 \mathrm{~ms}(\mathrm{n}=12)$ when coexpressed with synaptotamin I, increased by nearly 2 -fold. The difference was significant $(\mathrm{p}<0.05)$ (Figure 7C and 7D). However, the activation of the channel was not significantly affected (Figure 7E). These results suggested that synaptotagmin I delays the fast N-type inactivation of Kv1.4 by interacting with the N-terminus of the channel. 

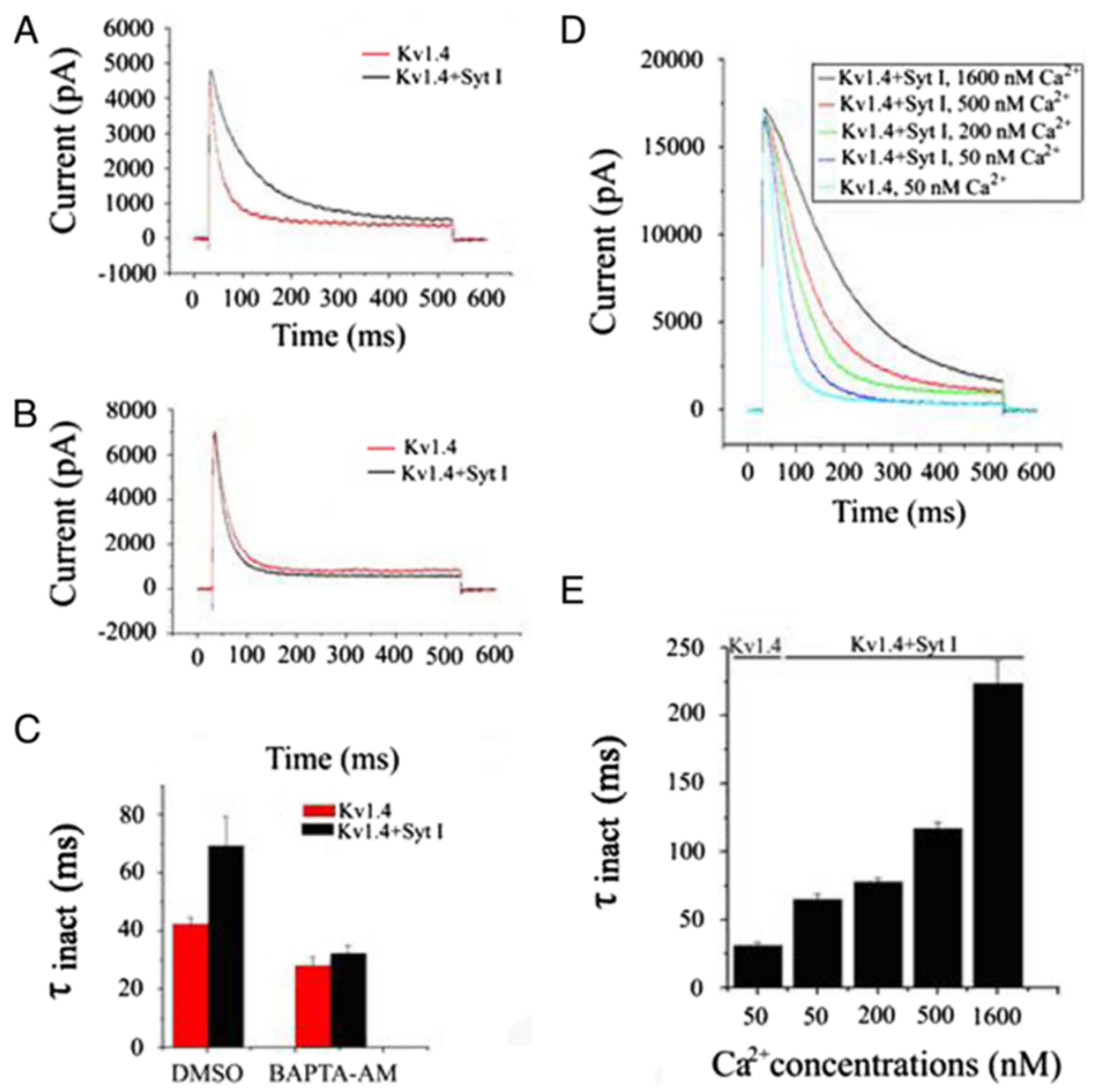

Figure 4 Intracellular $\mathrm{Ca}^{2+}$ is required for the effect of synaptotagmin I on Kv1.4 currents. One day after transfection, HEK293T cells were incubated for $20-26 \mathrm{~h}$ with BAPTA-AM $(10 \mu \mathrm{M}$ in $0.1 \% \mathrm{DMSO})$ or $0.1 \% \mathrm{DMSO}$ alone as a control. Currents were measured at $+30 \mathrm{mV} 2 \mathrm{days}$ after the injection. (A)-(B) Current traces of Kv1.4 and Kv1.4/synaptotagmin I after the cells were incubated with 0.1\% DMSO (A) or 10 MM BAPTA-AM (B). (C) Inactivation time constants ( $\left.\tau_{\text {inact }}\right)$ under the two different conditions. Data are expressed as mean \pm SD. After the cells were incubated with $0.1 \%$ DMSO, the $T_{\text {inact }}$ of Kv1.4 current expressed with and without synaptotagmin I were $38.1 \pm 2.3 \mathrm{~ms}(\mathrm{n}=9)$ and $68.8 \pm 2.6 \mathrm{~ms}(\mathrm{n}=9)$, respectively $(p<0.05)$. When the cells were incubated with BAPTA-AM, the $T_{\text {inact }}$ values of the channel under the two different conditions were not significantly different $(p>0.05)$. (D)-(E) Effects of synaptotagmin I on the inactivation of Kv1.4 channels at different concentrations of $\mathrm{Ca}^{2+}$ (D) and their corresponding $\tau_{\text {inact }}$ values (E).

\section{Discussion}

\section{Association of synaptotagmin I with neuronal}

\section{Kv 1.4 channel}

The importance of synaptotagmins in vesicle exocytosis and other cellular activities has attracted considerable interest over the past decades of years. Synaptotagmins belong to a large family including at least 15 members [20] that display distinct expression patterns both in neuronal and non-neuronal tissues [21,22]. In nerve endings, synaptotagmins are predominantly localized in synaptic vesicles but also present in the presynaptic plasma membrane [23]. Synaptotagmin I is one of the major neuronal isoforms [24] and is so far the best characterized. A series of evidences indicate that synaptotagmin $\mathrm{I}$ is a multifunctional protein, interacting specifically with the neuronal SNARE (soluble N-ethylmaleimide-sensitive factor attachment proteins receptor) proteins to participate in the regulation of vesicle exocytosis, and also displaying direct high affinity interaction with neuronal ion channels and many other proteins in $\mathrm{Ca}^{2+}$-dependent as well as $\mathrm{Ca}^{2+}$-independent manners, thus modulating their physiological functions $[14,25,26]$.

In neurons and neuroendocrine cells, regulated release of neurotransmitters, neuropeptides, and hormones relies on $\mathrm{Ca}^{2+}$-evoked exocytosis [27]. The three SNARE proteins, syntaxin, SNAP-25 and synaptobrevin constitute the minimal machinery for the exocytosis. Synaptotagmin I, acting as a $\mathrm{Ca}^{2+}$ sensor, can specifically interact with the SNARE machinery and play a critical role in SNAREmediated membrane fusion. The close proximity of $\mathrm{Ca}^{2+}$ channels with synaptic proteins was demonstrated biochemically by co-immunoprecipitatin of N- and P/Q-type 

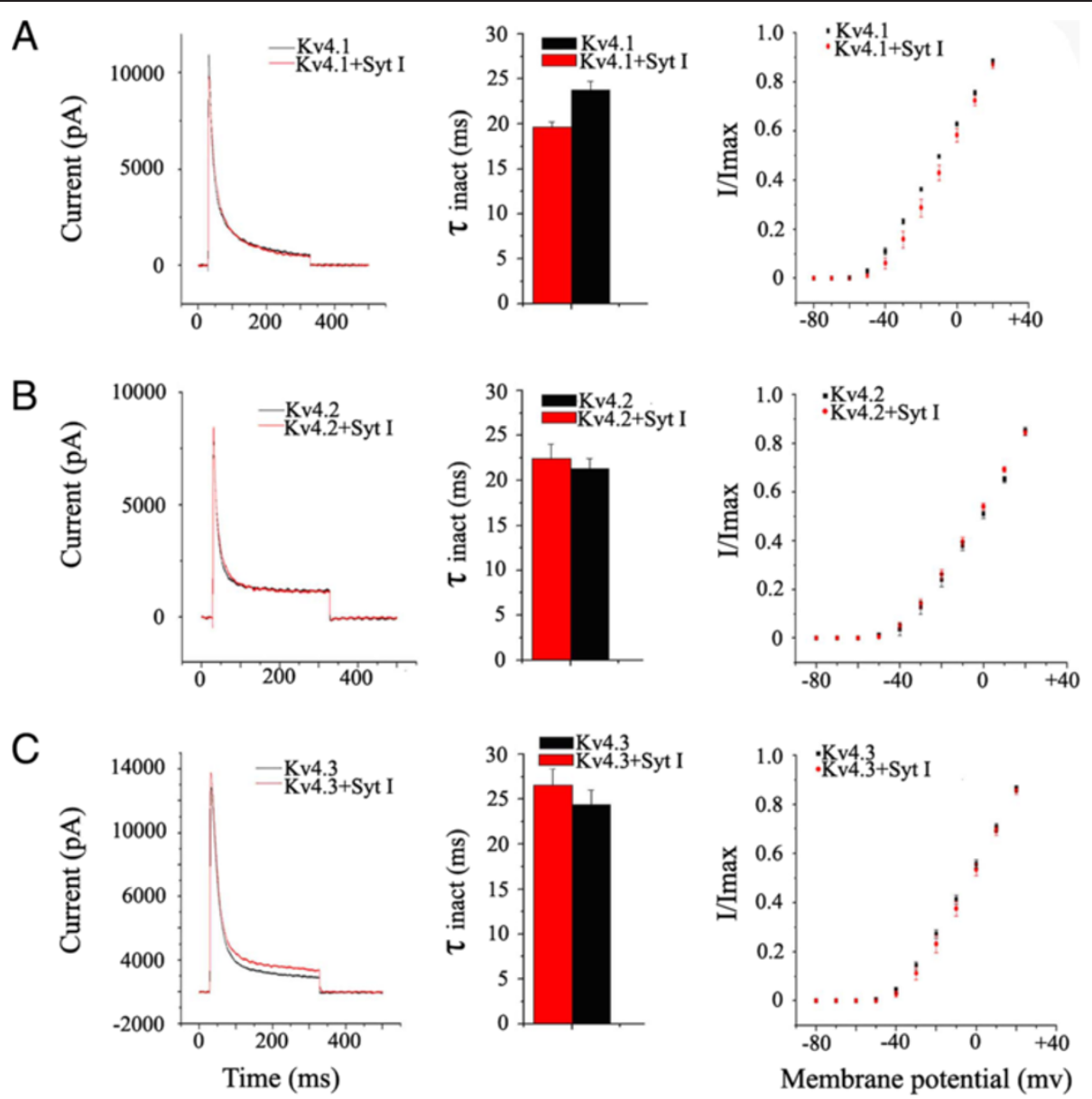

Figure 5 Effects of synaptotagmin I on the kinetics of Kv4 family subunits expressed in HEK293T cells. (A) Representative current traces of Kv4.1 channel and kv4.1/synaptotagmin I (left), their averaged inactivation time constants ( $\tau_{\text {inact }}$ ) (middle) and their activation curves; Current amplitudes recorded were normalized to the maximal responses at $+30 \mathrm{mV}$ and plotted as a function of the membrane potential (right). (B) Representative current traces of Kv4.2 channel and kv4.2/synaptotagmin I (left), their averaged $\tau_{\text {inact }}$ (middle) and their activation curves; Current amplitudes recorded were normalized to the maximal responses at $+30 \mathrm{mV}$ and plotted as a function of the membrane potential (right). (C) Representative current traces of Kv4.3 channel and Kv4.3/synaptotagmin I (left), their averaged $\tau_{\text {inact }}$ (middle) and their activation curves; Current amplitudes recorded were normalized to the maximal responses at $+30 \mathrm{mV}$ and plotted as a function of the membrane potential (right).

$\mathrm{Ca}^{2+}$ channels with syntaxin $1 \mathrm{~A}$ and synaptotagmin [26,28-30]. At the active zone, where a large number of vesicles are packed close to clusters of $\mathrm{Ca}^{2+}$ channels, a physical association of synaptotagmin with the channels is almost inevitable [31]. A series of studies have demonstrated that the activity of $\mathrm{Ca}^{2+}$ channels is modified by syntaxin, synaptotagmin I and SNAP-25 alone, or in various combinations [31-33]. During the investigation of possible association of $\mathrm{Na}^{+}$channels with synaptic proteins, Sampo et al. [34] found that synaptotagmin I displayed a direct high affinity interaction with neuronal voltagesensitive $\mathrm{Na}^{+}$channels, with the binding site on the cytosolic loop between domains I and II of the $\mathrm{Na}^{+}$ channel aIIA subunit. Moreover, the synaptotagmin/ sodium channel complex was shown to be distinct from the synaptotagmin-SNARE complex that associates with voltage-sensitive $\mathrm{Ca}^{2+}$ channels. As regarding the relationship between synaptotagmins and Kv channels, Fili et al. [35] reported that there is a physical interaction in brain synaptosomes between $\operatorname{Kv} \alpha 1.1$ and $\operatorname{Kv} \beta$ subunits with syntaxin $1 \mathrm{~A}$ occurring at least partially within the context of a macromolecular complex containing syntaxin, synaptotagmin and SNAP-25. However, the work of Fili et al. has not reported whether synaptotagmin interacts with the potassium channel subunits. To the best of our knowledge, up to now there have not been any reports on the interaction of synaptotagmins with $\mathrm{K}^{+}$channels. In the present study, for the first time we discovered that synaptotagmin I can interact with Kv1.4 and the interaction does not require other synaptic proteins to mediate. Furthermore, synaptotagmin-Kv1.4 channel complex is similar to syntaxin-sodium channel complex [34] but distincts from the synaptotgamin-SNARE protein complex that associates with calcium channels $[29,30]$. 

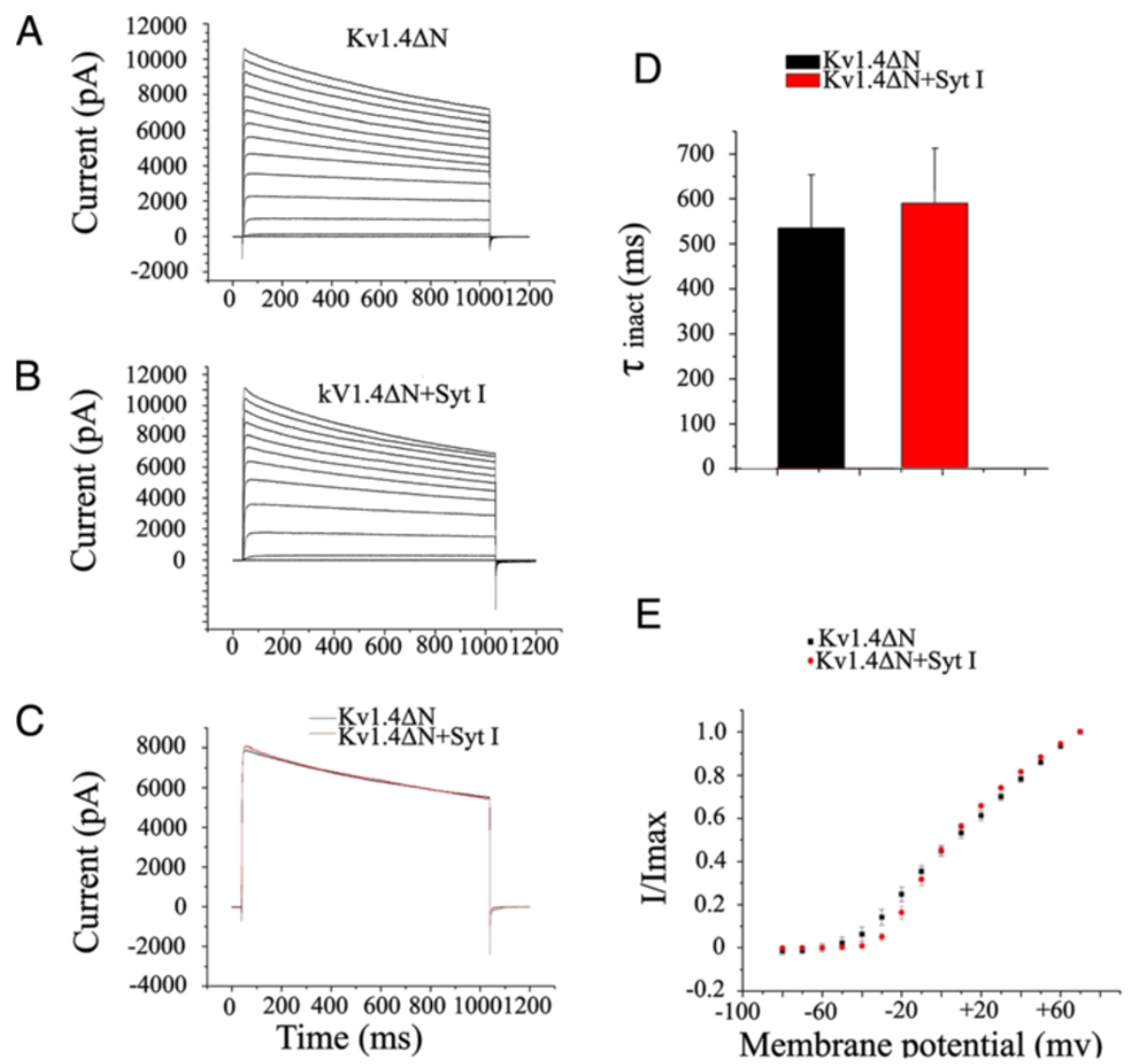

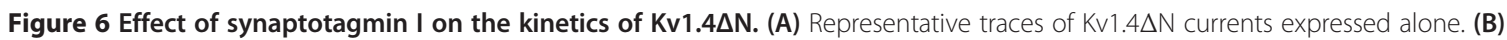
Representative traces of $\mathrm{Kv} 1.4 \Delta \mathrm{N}$ currents coexpressed with synaptotagmin I. Currents were elicited by depolarizing steps from -80 to $+70 \mathrm{mV}$ in $10 \mathrm{mV}$ increments every $45 \mathrm{~s}$ from a holding potential of $-80 \mathrm{mV}$. (C) Currents recorded upon depolarization to $+30 \mathrm{mV}$. (D) Inactivation time

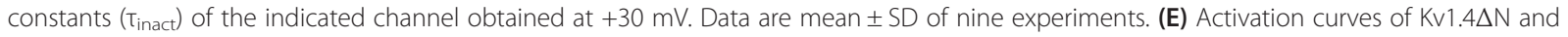
$\mathrm{Kv} 1.4 \Delta \mathrm{N} /$ synaptotagmin I. Current amplitudes recorded were normalized to the maximal response at $+30 \mathrm{mV}$ and plotted as a function of the membrane potential.

\section{Features of synaptotagmin I interaction with Kv1.4 channel}

As an A-type channel, Kv1.4 mediates rapidly inactivating outward rectifying currents and thus regulates membrane repolarization and thereby the electrical excitability [36,37]. The inactivation kinetics of the channel is modulated by many interacting proteins including those so called auxiliary subunits. Even minor alterations in the inactivation or recovery of the channel, such as those identified as the molecular basis of episodic ataxia [38] may result in considerable deleterious consequences. It has been reported that $\operatorname{Kv} \beta 1.1$ can further potentiate the fast inactivation of Kv1.4 channel $[39,40]$. Jow et al. [41] also found a faster inactivation of Kv1.4 current when Kv1.4 and Kv $\beta 1.1$ were coexpressed in oocytes. Kv $\beta 1.2$ has been shown to increase the rate of inactivation of Kv1.4 and slow the rate of recovery from inactivation, and the mutation experiments indicated that $\mathrm{Kv} \beta 1.2 \mathrm{C}$-terminus $(\mathrm{Kv} \beta 1.2-\mathrm{C})$ is responsible for interaction with the channel [42]. Co-expression of Kv $\beta 3$ with Kv1.4 shows that this $\beta$ subunit can increase the rate of inactivation from 4- to 7-fold in the Kv1.4 channel [43]. When Kv1.4 is expressed with DPP10, a dipeptidyl peptidase-related ancillary subunit, the channel shows faster time to peak current and negative shift in the half-inactivation potential of steady-state activation and inactivation [18]. The inactivation kinetics of Kv1.4 is also modulated by protein phosphorylation. Roeper et al. [12] demonstrated that the inactivation gating of the Kv1.4 is controlled by CaMKII and the calcineurin/inhibitor-1 protein phosphatase cascade. In addition, the activation of Kv1.4 is also regulated by its degree of phosphorylation $[44,45]$. Some other proteins also display regulatory action. For example, the sigma receptor has been demonstrated to be a novel protein that mediates the modulation of Kv1.4 by psychotropic drugs through a unique transduction mechanism depending neither on $G$ proteins nor protein phosphorylation [46]. 

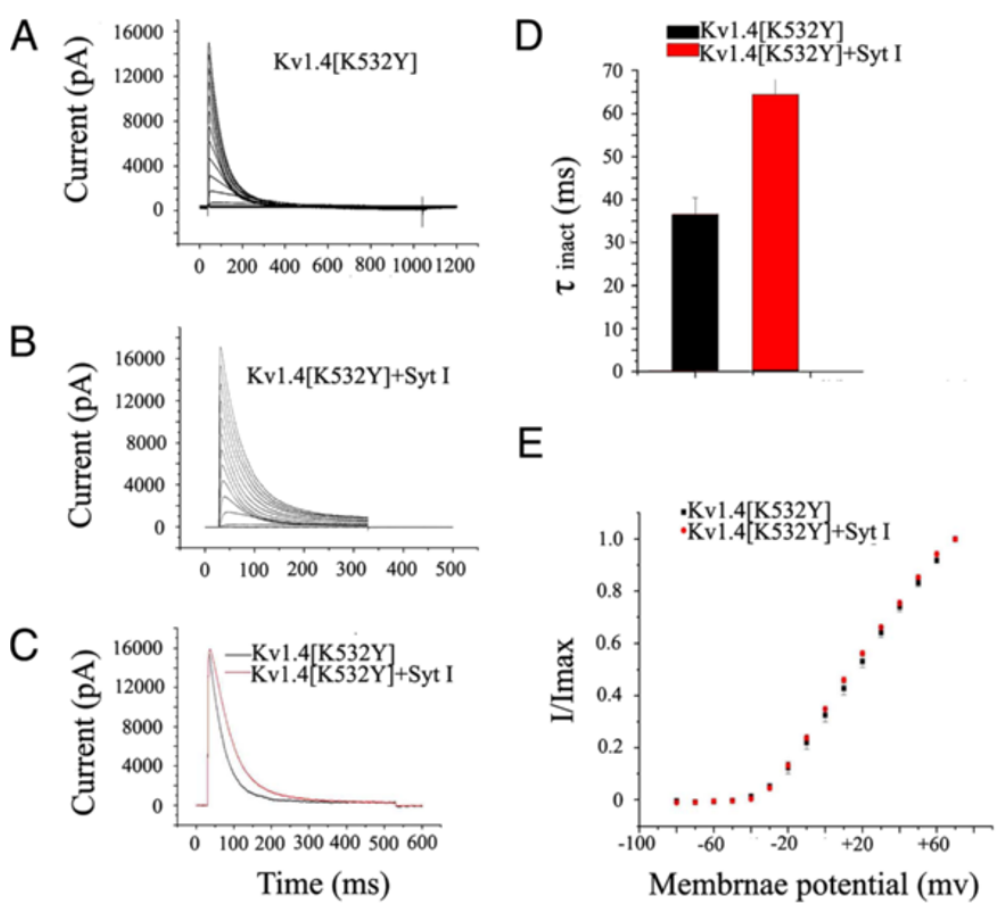

Figure 7 Effect of synaptotagmin I on the kinetics of Kv1.4[K532Y]. (A) Representative traces of Kv1.4[K532Y] currents expressed alone. (B) Representative traces of Kv1.4[K532Y] currents coexpressed with synaptotagmin I. Currents were elicited by depolarizing steps from $-80 \mathrm{lo}+70 \mathrm{mV}$ in $10 \mathrm{mV}$ increments every $45 \mathrm{~s}$ from a holding potential of $-80 \mathrm{mV}$. (C) Currents recorded upon depolarization to $+30 \mathrm{mV}$. (D) Inactivation time constants ( $\tau_{\text {inact }}$ ) of the indicated channels obtained at $+30 \mathrm{mV}$. Data are expressed as mean \pm SD. The inactivation of Kv1.4 [K532Y] was significantly $(p<0.05)$ affected by the coexpressed synaptotagmin I. The $\tau_{\text {inact }}$ of $\mathrm{Kv1.4}$ [K532Y] was $36.6 \pm 1.3 \mathrm{~ms}(n=9)$. When coexpressed with synaptotamin I, its $\tau_{\text {inact }}$ was $64.5 \pm 1.6 \mathrm{~ms}(\mathrm{n}=12)$. (E) Activation curves of Kv1.4[K532Y] and Kv1.4[K532Y]/synaptotagmin I. Current amplitudes recorded were normalized to the maximal response at $+30 \mathrm{mV}$ and plotted as a function of the membrane potential.

In the present study, a new modulatory protein of Kv1.4, synaptotagmin I, was discovered. When we employed whole-cell patch-clamp technique to investigate the effect of synaptotagmin I on the properties of Kv1.4 channel gating in HEK293T cells. The results showed that, in control cells that only expressed Kv1.4 channel, the channel displayed rapidly inactivating A-type $\mathrm{K}^{+}$currents in response to depolarizing voltage steps (Figure 3A), which is in agreement with the reported characteristics of Kv1.4 [4,5]. However, when Kv1.4 channel was coexpressed with synaptotamin I, the inactivation of the channel was markedly slowed, characterized by a more than 2 -fold increase in the $\tau_{\text {inact }}$ value at a membrane potential of $+30 \mathrm{mV}$, whereas the voltage-dependent activation of Kv1.4 channel was not obviously affected (Figure 3E). These results showed the first important feature of synaptotagmin I interaction with Kv1.4 channel: decreasing the inactivation rate of Kv1.4, without affecting its activation. That is to say, the action of synaptotagmin I on Kv1.4 is in contrast to those of the auxiliary subunit $K v \beta 1.1$ and $K v \beta 3$ as well as the dephosphorylation of Kv1.4, and has similarities to that of phosphorylation of the channel mentioned above.

Second, the influence of synaptotagmin I on the Kv1.4 channel was demonstrated to be $\mathrm{Ca}^{2+}$ dose-dependent.
In the control experiments, with application of $10 \mu \mathrm{M}$ BAPTA-AM, the inactivation of Kv1.4 channel was not altered, indicating that the inactivation of Kv1.4 channel itself is $\mathrm{Ca}^{2+}$-independent, which is in agreement with the conclusion of Jow et al. [41]. However, when Kv1.4 was coexpressed with synaptotagmin I, the inactivation of Kv1.4 channel was slowed and this change was affected by $\mathrm{Ca}^{2+}$ in a dose-dependent manner. These data suggest that synaptotagmin I, functioning as a $\mathrm{Ca}^{2+}$ sensor, bestows the calcium sensitivity on the inactivation of Kv1.4 channel.

Third, the impact of synaptotagmin I on Kv1.4 channel is specific. In the brain, A-type currents can be generated by Kv1.4 or any of the subunits in $\mathrm{K} v 4$ family (Kv4.1, Kv4.2 and Kv4.3). Kv1.4 is a presynaptic potassium channel whose mechanism of inactivation is most similar to that of the Kv4 family [18]. In view of this, we examined whether synaptotagmin I affects the Kv4 family subunits that are closely related to the A-type currents. The results (Figure 5) showed that, unlike Kv1.4, Kv4.1, Kv4.2 and Kv4.3 were not significantly affected by synaptotagmin I in terms of the inactivation time constant and the amplitude of channel currents. These results demonstrate that the modulation of Kv1.4 channel by synaptotagmin I has specificity. 
Inactivation of Kv1.4 channels is complex, involving at least two distinct mechanisms, $\mathrm{N}$ - and C-type inactivation. The N-type inactivation results from the rapid block of the conducting pore by the lipophilic $\mathrm{N}$-terminal region of the channels after channel opening [4], whereas the C-type inactivation occurs through a very distinct mechanism involving closure or collapse of the permeation pathway at both the intracellular and extracellular mouth of the pore [47]. Some auxiliary subunits and other factors can modulate either or both of the $\mathrm{N}$ - and C-type inactivation of Kv1.4 alone or in various combinations. For example, coexpression of rat Kv $\beta 1$ with Kv1.4 accelerated the N-type inactivation of the channel [39]; Kv 33 was found to accelerate the N-type inactivation of hKv1.4 [48]. Kvß2-C and $\mathrm{Kv} \beta 2$ can enhance $\mathrm{N}$-type inactivation produced by the Kv1.4 $\alpha$-ball allosterically [42]. It has been suggested that Kv $\beta 1.2$ can modulate C-type inactivation in the ferret $\mathrm{Kv} 1.4 \Delta \mathrm{N} 2-146$ and that is sensitive to external $\mathrm{K}^{+}$concentration [42]. Li et al. [49] reported that extracellular $\mathrm{pH}$ modulates both $\mathrm{N}$ - and C-type inactivation through an S5H5 linker histidine. Our experiments demonstrated that, when synaptotagmin I was coexpressed with Kv1.4 [K532Y], which had the N-type interaction but limited C-type inactivation, the inactivation of the channels was markedly delayed. So the fourth feature of synaptotagmin I interaction with $\mathrm{Kv} 1.4$ is that synaptotagmin I interacts with the N-terminus of Kv1.4 channels to affect the fast $\mathrm{N}$-type inactivation.

\section{Physiological implications of synaptotagmin I interaction with Kv1.4 channel}

Voltage-dependent potassium channels are activated by membrane depolarization and serve to repolarize the membrane [50]. During an action potential spike train, the inactivation of potassium currents can produce progressive broadening of the spikes. Neurons use inactivating $\mathrm{K}^{+}$ channels to modulate firing frequency and shape the electrical signaling properties. Slow inactivation delays the repolarization of action potential and attenuates the cell excitability. Kv1.4 channel in neurons has been implicated in the control of action potential frequency, threshold, and shape [51], as well as neurotransmitter release [52,53]. In the present study, synaptotagmin I was demonstrated to interact with the $\mathrm{N}$-terminus of Kv1.4 channel to delay its fast $\mathrm{N}$-terminal inactivation in a $\mathrm{Ca}^{2+}$-depedent manner. Although synaptotagmin I did not obviously influence the C-type inactivation of the channel mutant under the present experimental conditions, it can influence the whole inactivation kinetics of the Kv1.4 channel, because there is coupling between $\mathrm{N}$ - and C-type inactivated states $[19,49,54]$. It has been shown that, although $\mathrm{N}$ - and C-type inactivation mechanisms are molecularly distinct and subject to independent manipulation, the two inactivation mechanisms strongly interact [55]. The
$\mathrm{N}$-type inactivation resulting from the binding of the $\mathrm{N}$ terminal ball to a binding site within the open pore, which likely results in conformation changes of the channel, speeds up the rate at which C-type inactivation occurs $[5,54,56]$. At the nerve terminal, the delayed inactivation of Kv1.4 channel caused by synaptotagmin I would decrease the action potential frequency, thereby reducing depolarization-dependent $\mathrm{Ca}^{2+}$ entry and $\mathrm{Ca}^{2+}$-dependent transmitter release. The action of synaptotagmin I on the Kv1.4 channel was speculated to provide a negative feedback mechanism in the regulation of neuronal excitability and synaptic efficacy.

\section{Materials and methods}

\section{Materials and animals}

Trypsin was purchased from Sigma-Aldrich. Plasmid pcDNA3.1 was from Clontech. Protein A-Sepharose beads were from Santa Cruz. Polyclonal antibodies anti-Kv1.4, anti-synaptotagmin I (ab68853) and the peroxidase-conjugated secondary antibodies were from Abcam corporation (HK,China). BAPTA-AM (1,2-bis(o-Aminophenoxy)- ethane-N,N,N,N'-tetraacetic acid, tetraacetoxymethyl ester) and DMSO (Dimethyl sulfoxide) was from Sigma- Aldrich Co. (MO, USA). Adult SpragueDawley rats (weighting 200-250 g) and HEK293T cells were purchased from the Center South University (Changsha, China).

\section{Affinity purification of Kv1.4 channel complex}

Plasma membrane-enriched fraction was prepared from adult rat hippocampus as previously detailed [57,58], solubilized at $4^{\circ} \mathrm{C}$ in $1 \mathrm{mg} / \mathrm{mL}$ ComplexioLyte 48 (incl. protease inhibitors; Logopharm $\mathrm{GmbH}$, Freiburg, Germany) and cleared by ultracentrifugation $30 \mathrm{~min}$ at 125,000 g. $1.0 \mathrm{~mL}$ of solubilisate was incubated with $10 \mu \mathrm{g}$ immobilized rabbit polyclonal Abs raised against Kv1.4 or with control IgGs (Abcam). The bound proteins were eluted with Laemmli buffer and analyzed with SDS-PAGE (DTT was added after elution). The protein bands specifically purified were excised, in-gel digested with trypsin as described previously [59] and subjected to capillary liquid chromatographytandem mass spectrometry (CapLC-MS/MS). All the experimental procedures involving animals conformed to the guidelines of the National Institutes of Health for the care and use of laboratory animals.

\section{Mass spectrometry}

For CapLC-MS/MS analysis, the digested peptides were injected into a capillary LC system (Agilent 1200) and first desalted and preconcentrated on a pre-column (C18 PepMap ${ }^{\mathrm{im}}, 0.3 \mathrm{~mm}$ i.d., $5 \mathrm{~mm}$ long, LC Packings). The outlet of the LC system was directly connected to the electrospray source of an HCTultra ${ }^{\mathrm{TM}}$ mass spectrometer (Bruker Daltonics, Germany). Mass spectrometry analysis, 
data processing and bioinformatics analysis were performed according to our previous work [60]. In the output results, only the bold red peptides with ion scores above 15 in the mascot report were used for protein identification. Proteins were considered to be identified until the first hit of the reverted database appeared. We kept to the principle of using the minimum set of protein sequences to account for all observed peptides. Only proteins with two or more high-confidence (>95\%) unique peptides were considered as positively identified.

\section{Protein expression}

Rat Kv1.4, Kv4.1, Kv4.2, Kv4.3 and synaptotagmin I were subcloned into the pCDNA3.1 vector and expressed in HEK293T cells for interaction investigation. In addition, to determine whether synaptotagmin I affects C- or Ntype inactivation of Kv1.4, two Kv1.4 cDNA mutants: $\mathrm{Kv} 1.4 \Delta \mathrm{N}$ (amino acid residues 2-146 deleted to remove $\mathrm{N}$-type inactivation) and Kv1.4[K532Y] (a lysine-tyrosine point mutation introduced to diminish $\mathrm{C}$-type inactivation) were constructed and expressed in the same kind of cells as previously described [5]. The Kv1.4[K532Y] mutation was generated by PCR with the QuikChange mutagenesis method (Stratagene, La Jolla, CA). The fidelity of all clones was verified by sequencing.

\section{Immunofluorescence microscopy}

To investigate the subcellular localization of Kv1.4 and synaptotagmin I, HEK293T cells which were transiently transfected with Kv1.4 or synaptotagmin I cDNA, or cotransfected with both cDNAs were subjected to immunocytochemistry. For immunolocalization of Kv1.4 and synaptotagmin I in rat brain tissue, SD rat (20-day) brain sections $(14 \mu \mathrm{m})$ were obtained and processed. The primary antibodies and concentration used were rabbit antiKv1.4 (Abcam; 1:200) and mouse anti- synaptotagmin I (Millipore, 1:100). Secondary antibodies were applied (1:1 000) as Alexa Fluor 488- or 594-conjugated donkey or goat antibodies to rabbit IgGs or goat antibodies to mouse IgGs, washed extensively in PBS, and mounted with Hoechst 33342 (Beyotime Institute of Biotechnology, China). Controls consisted of omitting the primary antibodies. Images for stained cells were acquired on a Nikon A1R/A1 confocal microscope.

\section{Cell culture and transfection}

HEK293T cells were grown under standard tissue culture conditions $\left(5 \% \mathrm{CO}_{2} ; 37^{\circ} \mathrm{C}\right)$ in Dulbecco's modified Eagle's medium (DMEM) supplemented with 10\% fetal bovine serum, penicillin $(10 \mathrm{~g} / \mathrm{mL})$ and streptomycin (10 units/L). Transient transfections were performed via lipofectamine 2000 (Invitrogen, USA). Briefly, cells were seeded directly on 35-mm plastic culture dishes (day 0), allowed to grow to confluency (1-2 days), and then transfected with fresh lipofectamine $2000(1.5 \mu \mathrm{g} \mathrm{Kv} \mathrm{1.4,} 1.5 \mu \mathrm{g}$ synaptotagmin I, $0.75 \mu \mathrm{g}$ EGFP, $7 \mu \mathrm{l}$ lipofectamine 2000). After standing for 4-6 h, the transfection medium was replaced with normal medium. Cells with green fluorescent protein fluorescence were selected for whole-cell patch-clamp recording 36-48 h after transfection.

\section{Whole-cell patch-clamp recording and data analysis}

Kv1.4 potassium currents were recorded on experimental HEK293T cells using whole-cell patch-clamp technique at room temperature $\left(20-25^{\circ} \mathrm{C}\right)$. The patch pipettes with $\mathrm{DC}$ resistance of 2-3 $\mathrm{M} \Omega$ when filled with internal solution were fabricated from borosilicate glass tubing (VWR micropipettes, $100 \mu \mathrm{L}$, VWR Company) using a two-stage vertical microelectrode puller (PC-10, Narishige, Japan) and fire-polished by a heater (Narishige, Japan). Kv1.4 potassium currents were recorded with an Axon 700B patch clamp amplifier (AXON, American) and the $\mathrm{P} / 4$ protocol was used to subtract linear capacitive and leakage currents. Ionic currents were sampled at $5 \mathrm{kHz}$ and filtered at $1 \mathrm{kHz}$. The internal solution contained (in mM): KF 140, EGTA 1, $\mathrm{MgCl}_{2}$ 4, and HEPES 10, pH 7.4, and the external bathing solution contained (in $\mathrm{mM}$ ): $\mathrm{NaCl} 137, \mathrm{KCl} 5.9$, $\mathrm{MgCl}_{2}$ 1.2, $\mathrm{CaCl}_{2}$ 2.2, glucose 14 and HEPES 10, $\mathrm{pH} 7.4$.

$\mathrm{CaCl}_{2}$ was added to the intracellular solution in an amount to yield the desired concentration of free $\mathrm{Ca}^{2+}$, as calculated with the CABUF program. Currents were elicited by depolarizing steps from -80 to $+70 \mathrm{mV}$ in $10 \mathrm{mV}$ increments every $45 \mathrm{~s}$ from a holding potential of $-80 \mathrm{mV}$. Data were analyzed by using the program Clampfit10.0 (AXON, American) and ORIGIN 7.0 (Microcal Software, Northampton, MA). Leak subtraction was performed for each trace. Results are expressed as means \pm SD. Single exponentials fitted to the decaying phase of current responses to depolarizations at $+30 \mathrm{mV}$ were used to obtain the inactivation time constant $\left(\tau_{\text {inact }}\right)$. Comparisons between two groups were performed by using Student's t test. Values of P $<0.05$ were considered statistically significant.

\section{Abbreviations \\ CapLC-MS/MS: Capillary liquid chromatography-tandem mass spectrometry; Kv: Voltage-gated potassium; PCR: Polymerase chain reaction; \\ SDS-PAGE: Sodium dodecyl sulfate polyacrylamide gel electrophoresis; SNARE: Soluble N-ethylmaleimide- sensitive factor attachment proteins receptor; SNAP-25: Synaptosomal-associated protein 25 ; $\tau_{\text {inact }}$ : Inactivation time constant.}

\section{Competing interests}

The authors declare that they have no competing interests.

\section{Authors' contributions}

$X C, W Y, C P, W X$ and LS are responsible for the hypothesis development and overall design of the research and experiment, and supervised the experimental analyses. XC,WX and LS co-wrote the manuscript. XC, SH, GT, YY, PX and CR performed all experiments. All authors read and approved the final manuscript. 


\section{Acknowledgements}

This work was supported by grants from National Natural Science Foundation of China $(31271135,31070700)$, Hunan Provincial Natural Science Foundation of China (11JJ2019), National Basic Research Program or "973 Program" of China (2010CB529800), and the cooperative Innovation Center of Engineering and New Products for Developmental Biology of Hunan Province.

\section{Author details}

${ }^{1}$ Key Laboratory of Protein Chemistry and Developmental Biology of Ministry of Education, College of Life Sciences, Hunan Normal University, Changsha, Hunan 410081, P. R. China. ${ }^{2}$ Institute of Bast Fiber Crops, Chinese Academy of Agricultural Sciences, Changsha 410205, P. R. China.

Received: 7 October 2013 Accepted: 11 January 2014 Published: 14 January 2014

\section{References}

1. Rudy B: Diversity and ubiquity of K channels. Neuroscience 1988, 25(3):729-749.

2. Connor JA, Stevens CF: Voltage clamp studies of a transient outward membrane current in gastropod neural somata. J Physiol 1971, 213(1):21-30.

3. Lujan R, de Cabo de la Vega C, Dominguez del Toro E, Ballesta JJ, Criado M, Juiz JM: Immunohistochemical localization of the voltage-gated potassium channel subunit Kv1.4 in the central nervous system of the adult rat. J Chem Neuroanat 2003, 26(3):209-224.

4. Hoshi T, Zagotta WN, Aldrich RW: Biophysical and molecular mechanisms of shaker potassium channel inactivation. Science 1990, 250(4980):533-538.

5. Rasmusson RL, Morales MJ, Castellino RC, Zhang Y, Campbell DL, Strauss HC: C-type inactivation controls recovery in a fast inactivating cardiac $\mathrm{K}^{+}$channel (Kv1.4) expressed in Xenopus oocytes. J Physiol 1995, 489(3):709-721.

6. Trimmer JS, Rhodes KJ: Localization of voltage-gated ion channels in mammalian brain. Annu Rev Physiol 2004, 66:477-519.

7. Kashino Y, Harayama T, Pakrasi HB, Satoh K: Preparation of membrane proteins for analysis by two-dimensional gel electrophoresis. J chromatogr B 2007, 849(1-2):282-292.

8. Braun RJ, Kinkl N, Beer M, Ueffing M: Two-dimensional electrophoresis of membrane proteins. Anal Bioanal Chem 2007, 389(4):1033-1045.

9. Lee JK, Nishiyama A, Kambe F, Seo H, Takeuchi S, Kamiya K, Kodama I, Toyama J: Downregulation of voltage-gated $\mathrm{K}^{+}$channels in rat heart with right ventricular hypertrophy. Am J Physiol 1999, 277(5):1725-1731.

10. Sheng M, Liao YJ, Jan YN, Jan LY: Presynaptic A-current based on heteromultimeric $\mathrm{K}^{+}$channels detected in vivo. Nature 1993, 365(6441):72-75.

11. Campomanes CR, Carroll Kl, Manganas LN, Hershberger ME, Gong B, Antonucci DE, Rhodes KJ, Trimmer JS: Kv beta subunit oxidoreductase activity and Kv1 potassium channel trafficking. J Biol Chem 2002, 277(10):8298-8305.

12. Roeper J, Lorra C, Pongs O: Frequency-dependent inactivation of mammalian A-type $\mathrm{K}^{+}$channel KV1.4 regulated by $\mathrm{Ca}^{2+} /$ calmodulindependent protein kinase. J Neurosci 1997, 17(10):3379-3391.

13. Levitan IB: Signaling protein complexes associated with neuronal ion channels. Nat Neurosci 2006, 9(3):305-310.

14. Geppert M, Sudhof TC: RAB3 and synaptotagmin: the yin and yang of synaptic membrane fusion. Annu Rev Neurosci 1998, 21:75-95.

15. Schulte U, Thumfart JO, Klocker N, Sailer CA, BildI W, Biniossek M, Dehn D, Deller T, Eble S, Abbass K: The epilepsy-linked Lgi1 protein assembles into presynaptic Kv1 channels and inhibits inactivation by Kvbeta1. Neuron 2006, 49(5):697-706

16. Perin MS, Brose N, Jahn R, Südhof TC: Doman structure of synaptotagmin (65). J Biol Chem 1991, 266(1):623-629.

17. Lang $T$, Jahn R: Core proteins of the secretory machinery. Handb Exp Pharmacol 2008, 184:107-127.

18. Li HL, QU YJ, LU YC, Bondarenko VE, Wang S, Skerrett IM, Morales MJ: DPP10 is an inactivation modulatory protein of Kv4.3 and Kv1.4. Am J Physiol Cell Physiol 2006, 291(5):966-976.

19. Bett GC, Rasmusson RL: Inactivation and recovery in Kv1.4 $\mathrm{K}^{+}$channels: lipophilic interactions at the intracellular mouth of the pore. J Physiol 2004, 556(1):109-120.

20. Gustavsson N, Han W: Calcium-sensing beyond neurotransmitters: functions of synaptotagmins in neuroendocrine and endocrine secretion. Biosci Rep 2009, 29(4):245-259.
21. Schiavo G, Osborne SL, Sgouros JG: Synaptotagmins: more isoforms than functions? Biochem Biophys Res Commun 1998, 248(1):1-8.

22. Sugita S, Shin OH, Han W, Lao Y, Sudhof TC: Synaptotagmins form a hierarchy of exocytotic $\mathrm{Ca}^{2+}$ sensors with distinct $\mathrm{Ca}^{2+}$ affinities. EMBO $\mathrm{J}$ 2002, 21(3):270-280.

23. Matthew WD, Tsavaler L, Reichardt LF: Identification of a synaptic vesicle-specific membrane protein with a wide distribution in neuronal and neurosecretory tissue. J Cell Biol 1981, 91(1):257-269.

24. Rickman C, Archer DA, Meunier FA, Craxton M, Fukuda M, Burgoyne RD: Synaptotagmin interaction with the syntaxin/SNAP-25 dimer is mediated by an evolutionarily conserved motif and is sensitive to inositol hexakisphosphate. J Biol Chem 2004, 279(13):12574-12579.

25. Sudhof TC, Rizo J: Synaptotagmins: C2-domain proteins that regulate membrane traffic. Neuron 1996, 17(3):379-388.

26. Zamponi GW: Regulation of presynaptic calcium channels by synaptic proteins. J Pharmacol Sci 2003, 92(2):79-83.

27. Leung YM, Kwan EP, Ng B, Kang Y, Gaisano HY: SNAREing voltage-gated $\mathrm{K}^{+}$ and ATP-sensitive $\mathrm{K}^{+}$channels: tuning beta-cell excitability with syntaxin-1A and other exocytotic proteins. Endocr Rev 2007, 28(6):653-663.

28. Charvin N, L'evêque C, Walker D, Berton F, Raymond C, Kataoka M, Shoji-Kasai Y, Takahashi M, De Waard M, Seagar MJ: Direct interaction of the calcium sensor protein synaptotagmin I with a cytoplasmic domain of the alpha1A subunit of the P/Q-type calcium channel. EMBO J 1997, 16(15):4591-4596.

29. Leveque C, el Far O, Martin-Moutot N, Sato K, Kato R, Takahashi M, Seagar MJ: Purification of the N-type calcium channel associated with syntaxin and synaptotagmin. A complex implicated in synaptic vesicle exocytosis. J Biol Chem 1994, 269(9):6306-6312

30. Martin-Moutot N, Charvin N, Leveque C, Sato K, Nishiki T, Kozaki S, Takahashi M, Seagar M: Interaction of SNARE complexes with P/Q-type calcium channels in rat cerebellar synaptosomes. J Biol Chem 1996, 271(12):6567-6570.

31. Atlas D: Functional and physical coupling of voltage-sensitive calcium channels with exocytotic proteins: ramifications for the secretion mechanism. J Neurochem 2001, 77(4):972-985

32. Catterall WA: Structure and regulation of voltage-gated $\mathrm{Ca}^{2+}$ channels. Annu Rev Cell Dev Biol 2000, 16:521-555.

33. Wiser $\mathrm{O}$, Cohen $\mathrm{R}$, Atlas $\mathrm{D}$ : lonic dependence of $\mathrm{Ca}^{2+}$ channel modulation by syntaxin 1A. Proc Natl Acad Sci 2002, 99(6):3968-3973.

34. Sampo B, Tricaud N, Leveque C, Seagar M, Couraud F, Dargent B: Direct interaction between synaptotagmin and the intracellular loop I-II of neuronal voltage-sensitive sodium channels. Proc Natl Acad Sci 2000, 97(7):3666-3671

35. Fili O, Michaelevski I, Bledi Y, Chikvashvili D, Singer-Lahat D, Boshwitz H, Linial M, Lotan I: Direct interaction of a brain voltage-gated $\mathrm{K}^{+}$channel with syntaxin 1A: functional impact on channel gating. J Neurosci 2001, 21(6):1964-1974.

36. Pongs $\mathrm{O}$ : Voltage-gated potassium channels: from hyperexcitability to excitement. FEBS Lett 1999, 452(1-2):31-35.

37. Pongs $\mathrm{O}$, Leicher $\mathrm{T}$, Berger $\mathrm{M}$, Roeper J, Bähring R, Wray D, Giese KP, Silva AJ, Storm JF: Functional and molecular aspects of voltage-gated $\mathrm{K}^{+}$channel beta subunits. Ann N Y Acad Sci 1999, 868:344-355.

38. Adelman JP, Bond CT, Pessia M, Maylie J: Episodic ataxia results from voltage-dependent potassium channels with altered functions. Neuron 1995, 15(6):1449-1454.

39. Rettig J, Heinemann SH, Wunder F, Lorra C, Parcej DN, Dolly JO, Pongs O: Inactivation properties of voltage-gated $\mathrm{K}^{+}$channels altered by presence of beta-subunit. Nature 1994, 369(6478):289-294.

40. Yu W, Xu J, Li M: NAB domain is essential for the subunit assembly of both alpha-alpha and alpha-beta complexes of shaker-like potassium channels. Neuron 1996, 16(2):441-453

41. Jow F, Zhang ZH, Kopsco DC, Carroll KC, Wang K: Functional coupling of intracellular calcium and inactivation of voltage-gated Kv1.1/Kvbeta1.1 A-type $\mathrm{K}^{+}$channels. Proc Natl Acad Sci 2004, 101(43):15535-15540.

42. Accili EA, Kuryshev YA, Wible BA, Brown AM: Separable effects of human Kvbeta1.2 N- and C-termini on inactivation and expression of human Kv1.4. J Physiol 1998, 512(2):325-336.

43. Morales MJ, Castellino RC, Crews AL, Rasmusson RL, Strauss HC: A nove beta subunit increases rate of inactivation of specific voltage-gated potassium channel alpha subunits. J Biol Chem 1995, 270(11):6272-6277.

44. Nitabach MN, Llamas DA, Thompson IJ, Collins KA, Holmes TC: Phosphorylation-dependent and phosphorylation-independent modes 
of modulation of shaker family voltage-gated potassium channels by SRC family protein tyrosine kinases. J Neurosci 2002, 22(18):7913-7922.

45. Tao Y, Zeng R, Shen B, Jia J, Wang Y: Neuronal transmission stimulates the phosphorylation of Kv1.4 channel at Ser229 through protein kinase A1. J Neurochem 2005, 94(6):1512-1522.

46. Aydar E, Palmer CP, Klyachko VA, Jackson MB: The sigma receptor as a ligand-regulated auxiliary potassium channel subunit. Neuron 2002, 34(3):399-410

47. Jiang X, Bett GC, Li X, Bondarenko VE, Rasmusson RL: C-type inactivation involves a significant decrease in the intracellular aqueous pore volume of Kv1.4 $\mathrm{K}^{+}$channels expressed in Xenopus oocytes. J Physiol 2003, 549(3):683-695.

48. Majumder K, De Biasi M, Wang Z, Wible BA: Molecular cloning and functional expression of a novel potassium channel beta-subunit from human atrium. FEBS Lett 1995, 361(1):13-16.

49. Li X, Bett GC, Jiang X, Bondarenko VE, Morales MJ, Rasmusson RL: Regulation of $\mathrm{N}$ - and $\mathrm{C}$-type inactivation of $\mathrm{Kv} 1.4$ by $\mathrm{pHo}$ and $\mathrm{K}^{+}$: evidence for transmembrane communication. Am J Physiol Heart Circ Physiol 2003, 284(1):71-80.

50. Yellen $\mathrm{G}$ : The voltage-gated potassium channels and their relatives. Nature 2002, 419(6902):35-42.

51. Storm JF: Action potential repolarization and a fast afterhyperpolarization in rat hippocampal pyramidal cells. J Physio/ 1987, 385:733-759.

52. Kaang BK, Pfaffinger PJ, Grant SG, Kandel ER, Furukawa Y: Overexpression of an Aplysia shaker $\mathrm{K}^{+}$channel gene modifies the electrical properties and synaptic efficacy of identified Aplysia neurons. Proc Natl Acad Sci 1992. 89(3):1133-1137.

53. Shimahara T: Modulation of synaptic output by the transient outward potassium current in aplysia. Neurosci Lett 1981, 24(2):139-142.

54. Baukrowitz $\mathrm{T}$, Yellen $\mathrm{G}$ : Modulation of $\mathrm{K}^{+}$current by frequency and external $\left[\mathrm{K}^{+}\right]$: a tale of two inactivation mechanisms. Neuron 1995, 15(4):951-960.

55. Bett GC, Dinga-Madou I, Zhou Q, Bondarenko VE, Rasmusson RL: A model of the interaction between $\mathrm{N}$-type and C-type inactivation in Kv1.4 channels. Biophys J 2011, 100(1):11-21.

56. Loots $E$, Isacoff EY: Protein rearrangements underlying slow inactivation of the Shaker K ${ }^{+}$channel. J Gen Physiol 1998, 112(4):377-389.

57. Carlin RK, Grab DJ, Cohen RS, Siekevitz P: Isolation and characterization of postsynaptic densities from various brain regions: enrichment of different types of postsynaptic densities. J Cell Biol 1980, 86(3):831-845.

58. Sailer CA, Hu H, Kaufmann WA, Trieb M, Schwarzer C, Storm JF, Knaus HG: Regional differences in distribution and functional expression of small-conductance $\mathrm{Ca}^{2+}$-activated $\mathrm{K}^{+}$channels in rat brain. $J$ Neurosci 2002, 22(22):9698-9707.

59. Li X, Jia X, Xie C, Lin Y, Cao R, He Q, Chen P, Wang X, Liang S: Development of cationic colloidal silica-coated magnetic nanospheres for highly selective and rapid enrichment of plasma membrane fractions for proteomics analysis. Biotechnol Appl Biochem 2009, 54(4):213-220.

60. Li X, Xie C, Cao J, He Q, Cao R, Lin Y, Jin Q, Chen P, Wang X, Liang S: An in vivo membrane density perturbation strategy for identification of liver sinusoidal surface proteome accessible from the vasculature. J Proteome Res 2009, 8(1):123-132.

doi:10.1186/1756-6606-7-4

Cite this article as: Xie et al: Synaptotagmin I delays the fast inactivation of Kv1.4 channel through interaction with its $\mathrm{N}$-terminus. Molecular Brain 2014 7:4.

\section{Submit your next manuscript to BioMed Central and take full advantage of:}

- Convenient online submission

- Thorough peer review

- No space constraints or color figure charges

- Immediate publication on acceptance

- Inclusion in PubMed, CAS, Scopus and Google Scholar

- Research which is freely available for redistribution 